\title{
Poor Knowledge, Attitude and Practices of Pharmacovigilance among Health Care Professionals: A Cross-sectional Study
}

\author{
${ }^{1}$ Anusha Vohra, ${ }^{2}$ Rajaat Vohra, ${ }^{3}$ Meghna Verma
}

\begin{abstract}
Background: As the number of drugs available in the market are increasing, there arises a need to detect their adverse drug reactions and report them on time so that further harm can be avoided. The level of underreporting of adverse drug reactions is very high. Therefore, present study aimed to assess the knowledge, attitude and practice (KAP) of pharmacovigilance among the various health care professionals and suggest ways to improve them.
\end{abstract}

Materials and methods: A cross-sectional survey was done on 215 health care personnels working in a medical college in Jaipur. They were subjected to KAP questionnaire consisted of knowledge, attitude and practice based questions, designed specifically to assess the awareness about pharmacovigilance.

Results and conclusion: The mean KAP scores of physicians were found to be $5.75,4.44$ and 1.75 respectively. The KAP score of postgraduate students was $5.5,4.25$ and 1.5 respectively. The KAP score of final year MBBS students was $5,3.4$, and 1.4 respectively, and that of interns was $4,4.2$ and 1.4 respectively. The KAP score of pharmacists was 3.5 , 2 and 1 respectively, and that of nurses was $2.75,2.25$ and 0.8 respectively. It was found that mean score of physicians and postgraduate students was higher than interns and final year MBBS and much higher than nurses and pharmacists. Still they all fall under the poor score range to unsatisfactory score range which suggest that there is an urgent need for ongoing educational programs to train health care professionals about pharmacovigilance.

Keywords: Health care professionals, KAP, Pharmacovigilance.

How to cite this article: Vohra A, Vohra R, Verma M. Poor Knowledge, Attitude and Practices of Pharmacovigilance among Health Care Professionals: A Cross-sectional Study. J Mahatma Gandhi Univ Med Sci Tech 2016;1(2):42-46.

Source of support: Nil

Conflict of interest: None

\footnotetext{
${ }^{1,2}$ Associate Professor, ${ }^{3}$ Student (Final Year)

${ }^{1,3}$ Department of Pharmacology, Mahatma Gandhi Medical College and Hospital, Jaipur, Rajasthan, India

${ }^{2}$ Department of Community Medicine, Mahatma Gandhi Medical College and Hospital, Jaipur, Rajasthan, India
}

Corresponding Author: Anusha Vohra, D-4, Ganesh Marg Bapu Nagar-30215, Jaipur, Rajasthan, India, Phone: +919571931579, 0141-4050827, e-mail: drvohraansha@gmail.com

\section{INTRODUCTION}

With India growing to be the preferred clinical trials destination, there has arisen a need for pharmacovigilance as a branch of pharmacological science, critical to effective clinical practices and public health with immense possibility for growth. The WHO defines it as, "the pharmacological science relating to the collection, detection, assessment, monitoring, and prevention of adverse effects with pharmaceutical products. ${ }^{1}$

It has been noted that not only has the number of drugs available in the market increased, but so have the adverse drug reactions (ADR). This calls for a need of a system which will keep check on the increasing number of ADRs. One of the major reasons why pharmacovigilance programs have failed to achieve their motive is due to under reporting of the ADRs. The lack of awareness and knowledge on how to report ADRs have led to poor reporting in the past. ${ }^{2}$ ADRs are global problems of major concern. They affect both children and adults with varying magnitudes; causing both morbidity and mortality in varying degrees.

Pharmacovigilance has constantly grown in importance over the last 20 years, due to increase in the amount of adverse drug reactions (ADRs) and also because hospital inpatient records are showing increasing number of admissions due to ADRs. ${ }^{3,4}$ Pharmacovigilance program efficacy is now based on the ability to identify the risks and the risk factors quickly and effectively so that harm can be avoided or minimized.

When communicated properly to the health care providers and paramedicals, this information allows for evidence-based use of medicines and can prevent many adverse reactions in time. Final year students, interns, postgraduates, physicians, pharmacist and nurses can play a major role in pharmacovigilance programs. ${ }^{5,6}$ But, underreporting is very common. The level of underreporting is very high, with median underreporting rate (defined as percentage of ADRs detected from intensive data collection that were not reported to relevant spontaneous reporting systems) of $94 \%{ }^{7}$ Further, the underreporting rate for serious and unlabeled reactions is also very high. ${ }^{8}$ 
In order to deal with the current scenario of underreporting, it is important to improve the knowledge, attitude, and practices of the healthcare professionals regarding ADRs, and pharmacovigilance. This study aims to assess the knowledge, attitude, practice (KAP) of pharmacists, nurses, doctors at a teaching hospital in Jaipur. The inference derived may then be helpful to plan a suitable intervention among the health care workers so as to improve the current scenario.

\section{AIMS AND OBJECTIVES}

- To assess the KAP of pharmacovigilance among the health care professionals.

- To compare and analyze the results among various groups.

- To suggest the measures to improve the KAP of pharmacovigilance among health care professionals.

\section{MATERIALS AND METHODS}

It was a cross-sectional questionnaire based study.

The study population will include both medical and paramedical health care professionals - final year MBBS students, interns, postgraduates, physician, nurses, and pharmacists.

\section{Inclusion criteria}

- The study population included all final year MBBS students, interns, postgraduates students studying in the medical college.

- All physician, nurses and pharmacists who were working in the medical college.

\section{Exclusion criteria}

- Those not willing to participate

- Those who returned the questionnaire unanswered. Due approval will be taken from the institutional ethics committee of the college before conducting the study.

A predesigned and pretested questionnaire was used to assess the KAP of pharmacovigilance among the study population. The KAP questionnaire consists of 22 questions out of which 13 questions were knowledgebased, six questions attitude-based and three questions were practice-based designed, specifically to answer the awareness about pharmacovigilance.

The survey questionnaire was distributed to the final year MBBS students, interns, postgraduate students, physician and staff nurses belonging to different specialties practicing across the hospital. The participants were individually briefed about the questionnaire and they were requested to return the
Table 1: Grading of scores of knowledge, attitude and practices

\begin{tabular}{llccc}
\hline \multirow{3}{*}{$\begin{array}{c}\text { Awareness } \\
\text { level }\end{array}$} & Poor & Unsatisfactory & Satisfactory & $\begin{array}{c}\text { Maximum } \\
\text { possible } \\
\text { score }\end{array}$ \\
\cline { 2 - 5 } Knowledge & $<6$ & $6-10$ & $>10$ & 13 \\
Attitude & $<2$ & $2-4$ & $>4$ & 6 \\
Practice & $<1$ & $1-2$ & $>2$ & 3 \\
\hline
\end{tabular}

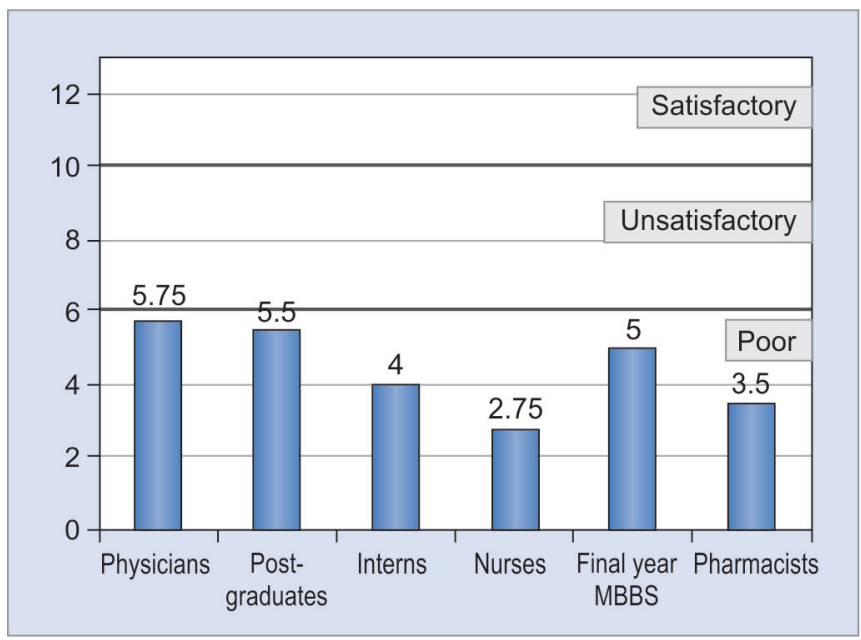

Graph 1: Mean knowledge score of physicians, postgraduates, interns, nurses, final year MBBS students and pharmacists

duly filled forms. The participants were given 30 minutes to answer the questionnaire and they were not allowed to consult anyone during that time. They were allowed to withhold their names but they were asked to write their designations. The questionnaire was then analyzed and grading was done into three categories: poor, unsatisfactory and satisfactory as shown in Table 1.

The data were entered on Microsoft office Excel and analyzed using SPSS software. One way ANOVA was used to find the significant association.

\section{RESULTS}

The study was carried out in 215 respondents from the medical and paramedical staff working at Mahatma Gandhi Medical College, Jaipur. These included 25 physicians, 20 postgraduate students (PGs), 20 interns, 100 final year MBBS students, 40 nurses and 10 pharmacists.

Table 2 shows the mean scores of knowledge of pharmacovigilance among health care professionals. The mean score of knowledge of pharmacovigilance among physicians and PGs is higher than interns and final year MBBS and much higher than nurses and pharmacists.

Though mean knowledge score is significantly higher in physicians and PGs in comparison to interns, nurses, final year MBBS students and pharmacists, all the knowledge score falls under poor score range (Graph 1).

Table 3 shows the mean scores of attitude of pharmacovigilance among health care professionals. It 
Table 2: Knowledge of pharmacovigilance among physicians, postgraduates, interns, final year MBBS students, nurses and pharmacists

\begin{tabular}{llllll}
\hline $\begin{array}{l}\text { Medical } \\
\text { professionals }\end{array}$ & $n$ & Mean & Standard deviation & F-value & p-value \\
\hline Physician & 25 & 5.75 & 1.414 & & \\
PGs & 20 & 5.5 & 2.82 & & \\
Interns & 20 & 4 & 2.121 & 21.48 & 0.000 \\
Nurses & 40 & 2.75 & 1.414 & & \\
Final year & 100 & 5.0 & 0.707 & & \\
MBBS & & & & & \\
Pharmacists & 10 & 3.5 & 1.414 & & \\
\hline
\end{tabular}

Table 3: Attitude of pharmacovigilance among physicians, postgraduates, interns, final year MBBS students, nurses and pharmacists

\begin{tabular}{llllll}
\hline $\begin{array}{l}\text { Medical } \\
\text { professionals }\end{array}$ & $n$ & Mean & Standard deviation & F-value & p-value \\
\hline Physician & 25 & 4.44 & 2.121 & & \\
PGs & 20 & 4.25 & 2.828 & & \\
Interns & 20 & 4.2 & 2.121 & 9.34 & 0.000 \\
Nurses & 40 & 2.25 & 0.707 & & \\
Final year & 100 & 3.4 & 1.414 & & \\
MBBS & & & & & \\
Pharmacists & 10 & 2.0 & 0.707 & & \\
\hline
\end{tabular}

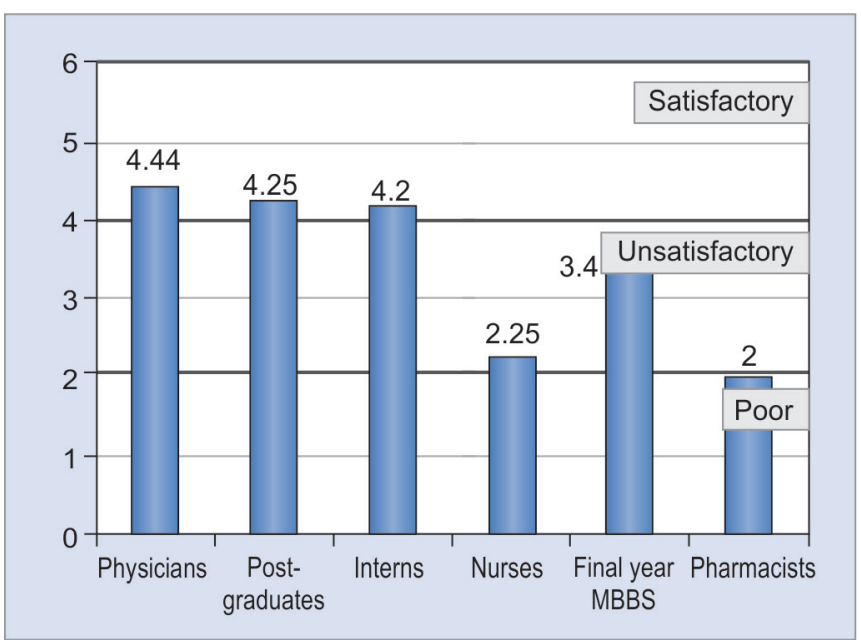

Graph 2: Mean attitude scores of physicians, postgraduates, interns, nurses, final year MBBS students and pharmacists

shows that mean score of physicians and PGs is higher than interns and final year MBBS and much higher than nurses and pharmacists.

The mean attitude score of physicians, PGs and interns fall under satisfactory score range while that of final year students and nurses falls under unsatisfactory score range and that of pharmacists under poor score range (Graph 2).

The mean scores of practice of pharmacovigilance among health care professionals shows that mean score of physicians and PGs is higher than interns and final year MBBS and much higher than nurses and pharmacists (Table 4).

Graph 3 shows that the mean practice score of pharmacovigilance among physicians, PGs, interns and

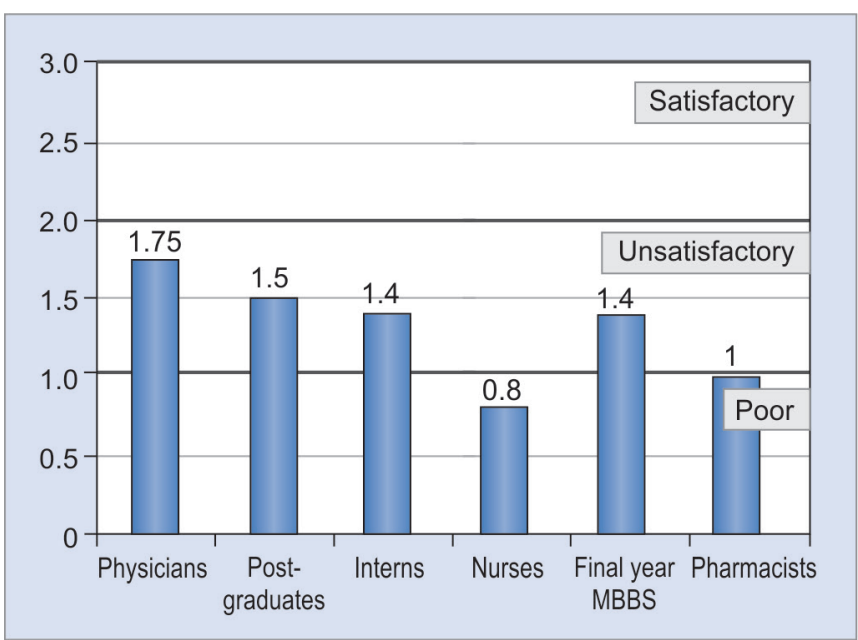

Graph 3: Mean practice scores of physicians, postgraduates, interns, nurses, final year MBBS students and pharmacists

final year students were under unsatisfactory score range while that of nurses and pharmacists under poor score range.

\section{DISCUSSION}

The main aims of pharmacovigilance are the early detection of the adverse reactions and interactions, monitoring the frequency of the adverse reactions, identification of the risk factors for the adverse reactions and dissemination of the information which is required to improve the prescription of drugs. A proper coordination amidst the health care professionals and the medical institutions is the most required for a successful pharmacovigilance program. They are the point of first 
Table 4: Practice of pharmacovigilance among physicians, postgraduates, interns, final year MBBS students, nurses and pharmacists

\begin{tabular}{llllll}
\hline $\begin{array}{l}\text { Medical } \\
\text { professionals }\end{array}$ & $n$ & Mean & Standard deviation & F-value & p-value \\
\hline Physician & 25 & 1.75 & 0.707 & & \\
PGs & 20 & 1.5 & 0.707 & & \\
Interns & 20 & 1.4 & 1.414 & \multirow{2}{*}{3.65} & 0.003 \\
Nurses & 40 & 0.8 & 1.414 & & \\
Final year & 100 & 1.4 & 0.707 & & \\
MBBS & & & & & \\
Pharmacists & 10 & 1.0 & 1.414 & \\
\hline
\end{tabular}

contact when it comes to adverse drug reactions, foremost being the physicians, interns, medical students, nurses and pharmacists. They are also an invaluable source for collecting, analyzing, and reporting ADRs.

In our study, we observed that the mean KAP scores among physicians were 5.75, 4.44, and 1.75 respectively. Knowledge, attitude and practice scores among postgraduate students were found to be 5.5, 4.25 , and 1.5 respectively. A study conducted by Gupta et al at BJ Medical College, Pune and Seth GS Medical College, Mumbai, also revealed that the awareness on the reporting systems was very low among the resident doctors. ${ }^{9}$ The mean KAP scores in interns were 4, 4.2, and 1.4, while, in final year MBBS students, KAP scores were 5, 3.4, and 1.4 respectively. A cross-sectional, questionnaire-based, multicentric study which was done on six different medical colleges in Gujarat indicated that the overall knowledge of pharmacovigilance was poor in undergraduate medical students. ${ }^{10}$ The mean KAP scores among nurses were found to be $2.75,2.25$, and 0.8 , while, in pharmacists, these were 3.5, 2.0 and 1.0 respectively.

A study conducted by Rehan et al in Lady Hardinge Medical College, New Delhi, showed that the knowledge, attitude and the practices of both the undergraduates and the prescribers were comparable, but they needed further improvement. ${ }^{11}$ A similar study which was conducted at the Civil Hospital, Ahmedabad, by Desai et al concluded that under reporting and a lack of knowledge about the reporting system were clearly evident among the prescribers. $^{12}$

Though mean KAP score among physicians and postgraduate students were higher than interns and final year MBBS students and much higher than in nurses and pharmacists; overall the mean KAP score was under unsatisfactory to poor score range. Thus, serious measures needs to be taken to educate the physicians, PGs, interns, final year MBBS, nurses and pharmacists about pharmacovigilance.

\section{CONCLUSION AND RECOMMENDATIONS}

The health care professionals had a relatively better attitude but limited knowledge and practice of pharmacovigilance. The lowest scores of nurses and pharmacists in KAP survey of pharmacovigilance suggest that there is an urgent need for educational programs to train nurses and pharmacists about pharmacovigilance and ADR reporting.

Following measures can be taken to increase KAP of pharmacovigilance among health care professionals:

- Increase awareness about pharmacovigilance

- Implementing ADR reporting as an integral part of the undergraduate, internship and postgraduate training

- Providing active manpower to collect the ADR reports from busy clinicians

- Provision of the feedback to the reporting health care professionals

- Involvement of nurses and paramedical staff in reporting the ADRs.

\section{REFERENCES}

1. The Importance of Pharmacovigilance: Safety Monitoring of medicinal products [Internet]. United Nation: 2002. pp.52.

2. Lee KK, Chan TY, Raymond K, Critchley JA. Pharmacists' attitudes toward adverse drug reaction reporting in Hong Kong. Ann pharmacother 1994 Dec;28(12):1400-1403.

3. Von Laue NC, Schwappach DL, Koeck CM. The epidemiology of preventable adverse drug events: a review of literature. Wien Klin Wochenschr 2003 Jul;115(12):407-415.

4. Wu WK, Pantaleo N. Evaluation of outpatient adverse drug reactions leading to hospitalization. Am J Health Syst Pharm 2003 Feb 1;60(3):253-259.

5. Ahmad SR. Adverse drug event monitoring at the Food and Drug Administration. J Gen Intern Med 2003 Jan;18(1):57-60.

6. Wysowski DK, Swartz L. Adverse drug event surveillance and drug withdrawals in the United States, 1969-2002: the importance of reporting suspected reactions. Arch Intern Med 2005 Jun;165(12):1363-1369. 
7. Hazell L, Shakir SA. Under-reporting of adverse drug reactions: a systematic review. Drug Saf 2006;29(5):385-396.

8. Moride Y, Haramburu F, Requejo AA, Begaud B. Underreporting of adverse drug reactions in general practice. Br J Clin Pharmacol 1997 Feb;43(2):177-181.

9. Gupta P, Udupa A. Adverse drug reaction reporting and pharmacovigilance: knowledge, attitudes and perceptions among the resident doctors. J Pharm Sci Res 2011;3(2):1064-1069.

10. Vora MB, Paliwal N, Doshi VG, Tripathi CR. Knowledge on the adverse drug reactions and the pharmacovigilance activity among the undergraduate medical students of Gujarat. Int J Pharma Sci Res 2012;3(5):1511-1515.

11. Rehan HS, Vasudev K, Tripathi CD. Adverse drug reaction monitoring: the knowledge, attitude and the practices of the medical students and the prescribers. Natl Med J India 2002 Jan-Feb;15(1):24-26.

12. Desai CK, Iyer G, Panchal J, Shah S, Dikshit RK. An evaluation of the knowledge, attitude and the practice of adverse drug reaction reporting among the prescribers at a tertiary care hospital. Perspect Clin Res 2011 Oct-Dec;2(4):129-136. 